IJ§ER

ISSN: 2149-5939
International Journal of Social Sciences and Education Research

Online, http://dergipark.gov.tr/ijsser

Volume: 1(2), 2015

\title{
Antik insanın sosyokültürel yaşamını yansıtan bazı diş ve iskelet sistemi anomalileri
}

\author{
Some teeth and skeletons anomalies reflected social-cultural practives of archaic \\ people
}

\author{
Nalan Damla Yılmaz Usta ${ }^{1}$
}

\begin{abstract}
Received Date: $01 / 02$ / 2015
Accepted Date: $01 / 04$ / 2015

$\ddot{O} z$

Insan yaşamindaki bazl sosyokültürel pratikler insan biyolojisini etkileyerek diş ve iskelet sisteminde anomalilere sebep olmaktadır. Çalışmanın amacı, diş ve iskelet sisteminde anomalilere sebep olan insan yaşamındaki sosyokültürel aktiviteleri belirleyerek bu verilerin antropoloji çalışmalarına nasıl katkı sağladığını değerlendirmektir. Bu amaçla, mevcut anomalileri kapsayan yayın ve raporlar taranmıştır. Bu araştırma neticesinde belirlenen verilerle anomalilerin muhtemel nedenleri ve antik insanın sosyokültürel yaşamının nasıl yorumlandı̆̆ gösterilmeye çalışılmıştır. Diş ve iskelet sistemi anomalilerinin bazılarının bilinçli olarak uygulanagelmiş bir geleneğin sonucunda oluşan anomaliler olduğu, bazılarının ise günlük aktiviteler ile ilişkili olarak oturma hareketi veya mesleki bir davranışın etkisinde oluştuğu tespit edilmiştir.
\end{abstract}

Anahtar sözcükler: Diş ve iskelet anomalileri, kültürel pratikler, kültürel deformasyon, paleopatoloji, antropoloji

\begin{abstract}
Some social-cultural activites on the men's life effect on their biological structures and so bring about some anomalies on teeth and skeletons. The purpose of the study is identified these activities on the men's life bringing about anomalies on the teeth and the skeletons and assessed how these datas are important for antropological studies. To this end, is surveyed articles and publics having reference to the anomalies. It is tried to show the information obtained in these negotiations reflected to be an association between the possible reasons of the anomalies and men's social-cultural life. It is determined that some of these anomalies resulted from traditional applied consciously and some also occured sitting motion or occupational treatment related to daily activites.
\end{abstract}

Keywords: Tooth and skeletol anomalies, cultural practices, cultural deformation, palaeopathology, anthropology

\section{Giriş}

Biyolojik antropoloji kapsamında iskelet kalıntılarından yola çıkarak biyoarkeoloji insanın geçmişinin aydınlatılmasını; adli antropoloji ise adli ve kamuya ait problemlerde iskeletlerin kimliklendirilmesini amaç edinmiştir. Bu amaçla biyolojik antropologlar, insanların yaşamlarına 1 şık tutan ve kimliklerine açıklık getiren iskelet kalıntılarındaki her izi titizlikle incelemekte ve yorumlamaktadırlar (Aydın ve Erdal, 2007 s.6-7).

İnsan, biyo-kültürel uyarlanma sürecinde mağaralardan açık alanlara yönelerek yaşam alanını değiştirmiş, geçmişten günümüze bazen küçük izole toplumlarda bazen ise ileri düzeyde teknolojiye sahip büyük kentlerde olmak üzere değişik mekanlarda çeşitli yaşam biçimleri sürmüştür.

\footnotetext{
${ }^{1}$ Asst. Prof. Dr., Süleyman Demirel University, Faculty of Arts and Sciences, Department of Anthropology, IS-
} PARTA/TURKEY, nalanyilmazusta@sdu.edu.tr 
Yılmaz Usta, N.D. (2015). Antik insanın sosyokültürel yaşamını yansıtan bazı diş ve iskelet sistemi anomalileri. International Journal of Social Sciences and Education Research, 1 (2), 547-559.

Bu süreçte sürekli olarak iklimin ve doğa olaylarının şekillendirdiği çevrenin etkisinde değişmiş ve çevresini değiştirmiştir. Yaşamını sürdürebilmek ve neslini devam ettirebilmek için avlanmak, besin toplamak, besin üretmek, iskan alanı oluşturmak, barınak yapmak, su temin etmek, göç etmek gibi maddi dünyayla uğraşmış ve isteklerine ulaşabilmek için dua etmek, büyü yapmak gibi manevi güçlere yönelmiştir. Yaklaşık olarak 200 bin yıldır dünya sahnesinde yer alan insan, çok çeşitli topluluk ya da toplumlarda yaşamış; değişen iklim koşulları ve çevresel özelliklerde çeşitli kültürler geliştirmiş; tedavi eden, güzelleştiren, soylu kılan ve buna benzer amaçlarla değişik pratikler uygulamış; bazen ağır şartlarda da olabilen günlük aktiviteler sergilemiştir. Bu uygulama ve aktiviteler ile insanın bir veya birkaç organı aktif çalışmış veya kullanılmış, sonuçta da bu organlarda patoloji ya da lezyon olarak da değerlendirebileceğimiz anomaliler oluşmuştur. Bunlardan dişlerde ve kemik dokuda vuku bulanlar çalışmanın konusunu oluşturmaktadır.

Tarih öncesi zamanlardan günümüze değin uygulanagelmiş kültürel pratiklerin ve günlük aktivitelerin dişlerde ve kemik yapıda sebep olduğu lezyonları göstermek, bunları antropolojik bakış açısıyla ele alarak nasıl teşhis edildikleri ve nasıl yorumlandıkları sorularını irdelemek bu çalışmanın başlıca amaçlarını oluşturmaktadır. Bu amaçlar doğrultusunda eski insanların sağlık sorunlarını, yaşam şekillerini, kültürlerini, kısacası antropolojik analizlerini, ayrıca günümüz insanının kültürel pratiklerini ve bunlardan kaynaklı sağlık sorunlarını konu edinen süreli yayımlar, kitaplar ve araştırma raporları bir araya getirilerek incelenmiştir. Araştırma, özellikle dişlerdeki ve iskelet sistemini oluşturan kemik dokudaki kültürel pratiklerden ve günlük aktivitelerden kaynaklı anomaliler üzerine yoğunlaşmıştır. Araştırma neticesinde kültürel pratiklerin ve günlük aktivitelerin vücudun hangi bölümlerini etkiledikleri ve nasıl anomalilere sebep oldukları gösterilerek bu verilerle antik insanın sosyal ve kültürel yaşamının nasıl yorumlandığı ve aynı zamanda bazen adli bir vakadaki iskelet kalıntılarının kimliklendirilmesinde önemli birer ipucu olabildikleri de aktarılmaya çalışılmıştır. Geçmişe adeta ayna tutan bu anomaliler iskelet sistemine yansıyanlar ile dişlere yansıyan kültürel uygulamalar ve günlük aktiviteler olmak üzere iki temel alanda incelenmektedir.

\section{2. İskelet sistemine yansıyan kültürel uygulamalar ve günlük aktiviteler}

\subsection{ISkelet sistemine yanslyan kültürel uygulamalar}

\subsubsection{Başın biçimini değiştirme}

Bebeklik döneminde değişik başlıklar, sargılar ya da tahta, taş, ağaç kabuklarının kullanıldığı özel aletlerle başa yeni bir şekil verilmektedir. Bu, genellikle belli bir amaca yönelik (estetik, ritüel ya da büyüsel) bilinçli kültürel deformasyon olarak uygulanmaktadır. Ancak, başın biçimindeki değişiklik bebeğin sert zeminde yatırılmasına benzer şekilde herhangi bir amaç güdülmeden bilinçsizce uygulanmış bir kültürel deformasyon olarak da ortaya çıkabilmektedir (Özbek, 2000; 2015).

Başın biçimini değiştirme pratiğinin bilinen en eski kayıtları, buluntuları Şanidar mağarasından (İran) ele geçen Neanderthal insanlarıyla 45 bin yıl öncesine kadar uzanmaktadır. And Dağları'nın olduğu bölgede ise yaklaşık olarak 10 bin yıl öncesine kadar izleri görülebilmektedir. Mayalılar bu deformasyonu oluşturabilmek için başlıklar ve özel araçlar kullanmışlar, Mısırlı yüksek statülü insanlar deformeli başlarla portre edilmişlerdir. Eski Mayalılara ait portrelerde bu uygulamanın açıkça tasvir edildiği görülmüştür (Aufderheide ve Rodriguez-Martin, 1998 s.34). 
Y1lmaz Usta, N.D. (2015). Some teeth and skeletons anomalies reflected social-cultural practives of archaic people. International Journal of Social Sciences and Education Research, 1 (2), 547-559.

Anadolu'da yapılan kazılarda da bu pratikle ilgili pek çok örnek ele geçmiştir. Şeyh höyük (Hatay, Kalkolitik Çağ) iskeletlerinde tüm kadın kafataslarının bilinçli uygulanan deformasyon izlerini taşıdığı, buna karşın erkek bireylerin normal oldukları tespit edilmiştir (Şenyürek ve Tunakan, 1951). Değirmentepe (Malatya, Kalkolitik Çağ) (Özbek, 1985) ve Byblos (Lübnan, Kalkolitik Çağ) (Özbek, 1974) iskeletlerinde 3-4 aylık bebeklerde bile deformasyonun belirgin izlerine rastlanmıştır. Aynı örneklerde başı deforme olmayan bebeklerin bu etnik uygulama dışında tutulan erkek çocuklar olduğu öngörülmüştür. Anadolu yarımadasında (Dinnil-Bodrum, Miken Dönemi (Tunakan, 1964); Kurban Höyük-Urfa, M.Ö.5000 (Alpagut, 1986); Karataş-Antalya, Neolitik Çağ (Angel ve Bissel, 1986)); benzer olarak Kıbrıs adasında da (Khirokitia-Kıbrıs, Neolitik Çağ (Angel ve Bissel, 1986)) farklı dönemlere tarihlendirilen kadın bireylerde baş deformasyonu tespit edilmiştir.

Neden baş deformasyonu uygulanır? Sorusunun cevabı, zamana ve mekâna göre değişmektedir. İspanyol tarihçiler bu uygulamanın And Dağlarında yaşayan yerli bir kabilenin işareti olduğunu belirtmektedirler. Minoans toplumunda elit sınıf için seçkinlik göstergesi olarak bu pratik uygulanmaktadır. And Dağları'nın etrafında yaşayan bazı gruplar kendi başlarını kutsal gördükleri bu dağların zirvelerinin şeklinde deforme etmişlerdir (Aktaran Aufderheide ve RodriguezMartin, 1998 s.36). Geçmişten günümüze bu âdetin çoğu toplumda sadece kız çocuklarını hedef alması farklı bir güzellik anlayışına, belki de büyüsel nedenlere işaret etmektedir (Özbek, 2000; 2015).

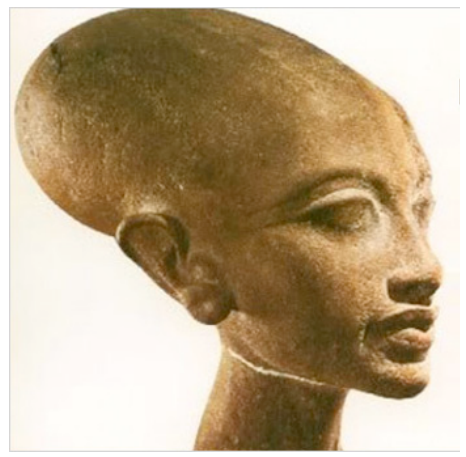

Resim 1. Yaklaşık M.Ö.3700’de yaşayan deformeli başa sahip Misır prensesinin portresi (http://tmjbeverlyhills.com/skull-deformationtmj-dentist-beverlyhills/, 14.11.2015).

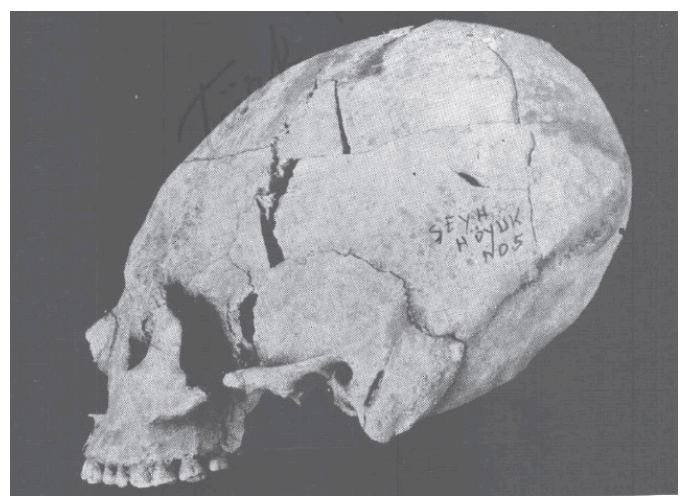

Resim 2. Şeyh Höyük'te (Kalkolitik Çă̆) baş deformasyonu olan kadın bir bireye ait kafatası (Şenyürek ve Tunakan, 1951).

\subsubsection{Başı dă̆lama}

Tıp dilinde koterizasyon (cauterisation) olarak bilinen dağlama genel tanımıyla vücudun bir bölümünün bir araçla ısı uygulanarak yakılmasıdır (Aufderheide ve Rodriguez-Martin, $1998 \mathrm{~s}$. 36; Eren, 1988; Özbek, 2003). Isı demir bir şiş, köz, fitil, odun parçası, taş ya da hayvan yağı gibi bir kültürden diğerine değişebilen farklı yöntemlerle uygulanabilmektedir (Aufderheide ve Rodriguez-Martin, 1998 s.36). Türk kültüründe bu uygulamayı araştıran Durmuş (2012) insana yap1lan dağlamanın amacının bedeni güçlendirmek ya da hasta uzvu tedavi etmek olduğuna dikkat çekmiştir. Hasta olan uzva ait olan damarlar dağlanarak o uzva akan safra, sevda, gam, balgam gibi hıltların akışı engellenmiş olur (Aktaran Durmuş, 2012). 
Yılmaz Usta, N.D. (2015). Antik insanın sosyokültürel yaşamını yansıtan bazı diş ve iskelet sistemi anomalileri. International Journal of Social Sciences and Education Research, 1 (2), 547-559.

Başa uygulanan dağlama başın tepesi, arkası veya alın bölgesine yapılır. Uygulama yapılan kısımdaki saç, deri, kemik zarı ve kemik dokuyu besleyen kan damarları dağlamadan kaynaklanan yüksek 1sı sonucu yanar (Aufderheide ve Rodriguez-Martin, 1998 s.36; Özbek, 2003). Bu yanma neticesinde ortaya çıkan lokal kemik doku ölümüyle tahribat oluşur, lezyonun olduğu bölge büyümez ve çevredeki normal kısımlara göre ince kalır (Özbek, 2003).

Başın dışına bir aletle 1sı uygulanarak hastalığın iyileşeceği inancıyla ilgili bilinen en eski bulgular Neolitik Çağ'a aittir. Fransa'nın güneyinde Neolitik Çağa tarihlenen 6 kadın bireyin kafataslarında " $T$ " şeklinde dağlama lezyonuna rastlanılması ilginç bir örnek olarak görülmüştür (Aufderheide ve Rodriguez-Martin, 1998 s.36). Anadolu'da Değirmentepe buluntu yerinde Kalkolitik Çağa (7-6 bin yıl önce) tarihlenen iki bebeğin kafatasında da bilinçli yapılan dağlama izleri tespit edilmiştir (Özbek, 2003).

\subsubsection{Kafa derisi yüzme}

Ölü ya da sağ insanların kafasının üst veya arka kısmında saçlı alanın kısmen ya da tamamen deriyle birlikte yüzülerek alınmasıdır. Esasen bir savaş geleneği olan bu uygulama sömürgecilik döneminde Eski Dünya' dan gelen insanlar tarafından bir işkence ve intikam aracı olarak kullanılmıştır (Aufderheide ve Rodriguez-Martin, 1998, s.37).

Kafatası derisinin yüzülmesiyle mevcut bölgede kan damarlarının ortadan kalkması, ayrıca uygulama esnasında kullanılan aletin kesici özellikte olması kemikte tahribata sebep olmaktadır. Tahrip olan kemik doku yaşayan bireylerde zamanla iyileşerek yenilenir (Aufderheide ve Rodriguez-Martin, 1998, s.37).

Virginia ve Nebraska'da prehistorik ve antik dönemlere ait çok sayıda örnekte bu uygulamanın izleri tespit edilmiştir (Aufderheide ve Rodriguez-Martin, 1998, s.38).

\subsubsection{Kafatası delgi ameliyatı / trepanasyon}

Kafatası delgi ameliyatı kafatasında beyne ve kan damarlarına zarar vermeden kemik yapının bir kısmının çıkarılması işlemidir (Aufderheide ve Rodriguez-Martin, 1998 s.31).

Avrupa ve Kuzey Afrika'da izleri Epipaleolitik Çağ'a (Orta Taş Çağı) kadar geriye giden bu cerrahi uygulama beyinde gerçekleştirilen en eski ameliyat türüdür (Aufderheide ve RodriguezMartin, 1998 s.31; Özbek, 2014). Kafatası delgi ameliyatı Neolitik Çağ'dan itibaren özellikle Avrupa ve Orta Doğu'da yaygın biçimde görülmeye başlamıştır. Avusturya'da M.S. 16. yüzyıla kadar kafatası delgi operasyonunun bilindiği ve uygulandığı Evliya Çelebi'nin notlarından kaydedilmiştir. Anadolu'da da hemen her dönem örneklerini gördügümüz bu uygulama bir sağaltma işlemi olmakla birlikte, özellikle tarih öncesi çağlarda ritüel ve büyüsel yönleriyle bir inanışın göstergesi olarak da kabul görmektedir (Özbek, 2014). 
Y1lmaz Usta, N.D. (2015). Some teeth and skeletons anomalies reflected social-cultural practives of archaic people. International Journal of Social Sciences and Education Research, 1 (2), 547-559.

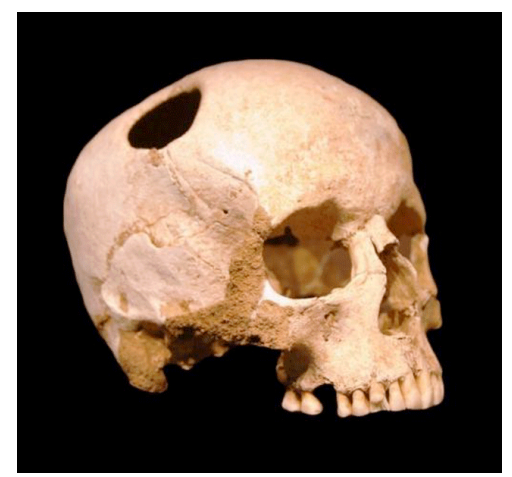

Resim 3. Roma Dönemi Bathoneia antik kentinden (İstanbul) çıkarılan bir kafatasında trepanasyon izi (http://www.guncelmersin.-com/haber/egitim-kultur_1/turkiyede-basarili-bir-antikbeyin-ameliyati/422.html, 16.11.2015).

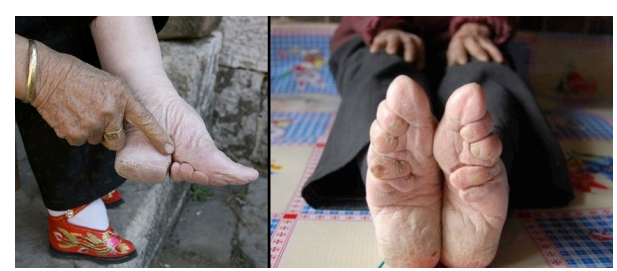

Resim 4. Çinli bir kadının küçültülmüş ayakları (http://dunyalilar.org/kucuk-ayak-buyukstatu.html, 16.11.2015).

\subsubsection{Ayak küçültme / ayak dondurma / lotus ayak}

Kız çocuklarının ayaklarının büyümemesi için yapılan estetik işlemdir. Çin'de uygulanan bu geleneğin kökeni 10. yüzyılın ikinci yarısına dayanır. Bu dönemde hüküm süren imparatorun gözdesi bir cariyenin küçük ayaklarıyla altından yapılmış lotus şeklindeki platform üzerinde dans etmesi büyük ilgi görür ve yaklaşık bin yıl boyunca uygulanan bu geleneği ortaya çıkarır. Gözde olmanın ayakların küçük olmasına bağlanmasıyla ortaya çıkan bu uygulama ayak gelişmeden önce 4 ve 7 yaşlarında olmak üzere iki aşamada yapılmaktadır (Özbek, 2015; http://m.galamagazin.com/fotograflarla-cinde-yasayan-ayaklari-baglanmis-son-kadinlar/729/, 05.10.2015). Ayaklar sıcak otlar ve hayvan kanında bekletildikten sonra parmaklar topuğa doğru bükülmekte ve bandajlarla sıkıca sarılmakta, işlemler her uygulandığında ayak kemikleri kırılmaktadır (http://m.galamagazin.com/fotograflarla-cinde-yasayan-ayaklari-baglanmis-son-kadinlar/729/, 05.10.2015).

Böyle ayaklara sahip olmak kadınların hayatları boyunca bağımsız olmalarını engellemekle birlikte, onları cazibeli ve iffetli göstermektedir. Çin'de kadınların sokakta tek yürümeleri ve erkeklerin arasında bulunmaları hoş karşılanmayan bir durumdur; böyle ayaklara sahip kadınların bu davranışları yapmasının mümkün olmadığının bilinmesi bu ayakları ayrı bir onur kaynağı haline getirmiştir (Özbek, 2015; http://old.kesfetmekicinbak.com/atlasdan/eskiatlas/00165/, 05.10.2015). 12. Yüzyılda ortaya çıkan Neokonfüçyanizm akımı da "akıllı beden, acı çeken beden" öğretisini vurgulayarak bu geleneğin hızla yayılmasında etken olmuştur (http://old.kesfetmekicinbak.com/atlasdan/eskiatlas/00165/, 05.10.2015). Başlangıçta üst sınıfların statü göstermek için uyguladığı bu gelenek zamanla alt sınıflara da yayılmış ve bir güzellik sembolü halini almıştır (http://m.galamagazin. com/fotograflarla-cinde-yasayan-ayaklari-baglanmis-son-kadin$\operatorname{lar} / 729 /, 05.10 .15$; Özbek, 2015).

\subsubsection{Boyuna halka takma}

Boyuna halka takılması bazı kabilelerde küçük yaşlardan itibaren özellikle kadınlara yapılan bir uygulamadır. Bu geleneğin ortaya çıkışıyla ilgili rivayetler; Afrikalı kabilelerde kadınlar ormanda vahşi hayvan saldırılarından korumak için veya yine Afrika'da sömürgeci ülkelerin askerlerinin kabile kızlarını esir olarak götürmek istemeleri sonucunda kızların çirkin görünmek için 
Yılmaz Usta, N.D. (2015). Antik insanın sosyokültürel yaşamını yansıtan bazı diş ve iskelet sistemi anomalileri. International Journal of Social Sciences and Education Research, 1 (2), 547-559.

boyunlarına metal halkalar geçirmesi şeklindedir (http://opereysin.com/arastirma/1187-uzun-boyunlar-cokkun-omuzlar/ ,05.10.2015). Esasen korunma içgüdüsüyle günümüze değin süregelen bu uygulama, zaman içerisinde zenginlik, soyluluk ve estetiğin sembolü haline gelmiştir (Özbek, 2015; http://opereysin.com/arastirma/1187-uzun-boyunlar-cokkun-omuzlar/,05.10.2015).

Günümüzde Güneydoğu Asya'da yaşayan Padaung kabilesinin kızları boyunlarını ortalama 5 yaşlarındayken takmaya başladıkları bakırdan halka kolyelerle uzatmaktadırlar. Halkaların her iki yılda bir değiştirildiği bu uygulama esasen ergin olmayla ilgili bir pratiktir. Halkalar takılmadan önce kızların boynuna merhemlerle masaj yapılır. Halka sayısı attıkça boyun olduğundan daha uzun görünmekte, bu esnada boyun omurlarında herhangi bir patoloji oluşmamaktadır. Diğer yandan, boyun omurları disklerinden ayrılmakta, halkaların ağırlı̆̆ıyla da omuzlar aşağı basılarak vücudun şekli bozulmaktadır (Özbek, 2015; http://opereysin.com/arastirma/1187-uzun-boyunlarcokkun-omuzlar/05.10.2015).

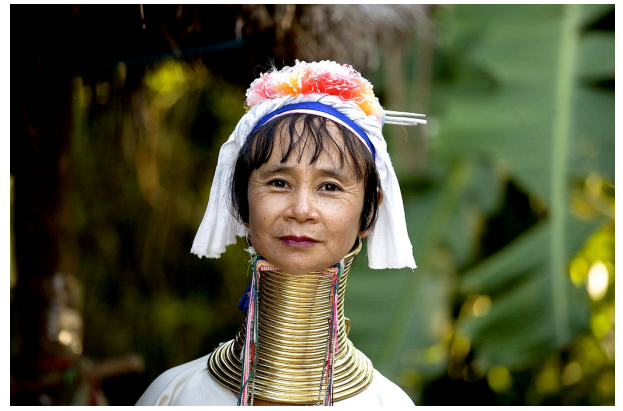

Şekil 5. Padaung kabilesinden boynu halka takılarak uzamış bir kadın (http://www.fotografturk.com/uzun-boyunlu-kadinlar-p297720, $16,11,2015)$.

\section{2. İskelet sistemine yanslyan günlük aktiviteler}

\subsection{1. Çömelme faseti (squatting facet)}

Genel olarak çömelme hareketi veya duruşuna bağlı olarak ayak bilek kemiği talusta ve alt bacak kemiği tibianın distal ucunda oluşan yeni eklem yüzeyidir. Çömelme davranışı sonucunda uyluk kemiği ve diz kemiğindeki (femurda troclear yüzeyin genişlemesi, distal condyler arası fossanın derinleşmesi ya da patellar yüzeyin lateral kenarının yuvarlaklaşması gibi) değişimler de iskelette gözlemlenebilmektedir (Jones, 2007).

Neden çömeliriz? Avcılık ve toplayıcılık yaparken, tarımla uğraşırken ve diğer büyük çaba isteyen işleri yaparken veya yalnızca dinlenirken kemiklerimizde izler oluşturan, onların morfolojilerini etkileyen özel bir hareket veya duruş şekli olarak çömeliriz (Jones, 2007). Örneğin Çayönü Neolitik Çağ insanlarının bu oluşumla ilişkili olarak günlük yaşamlarında çömelerek iş yapma alışkanlıkları olduğu belirlenmiştir (Özbek, 2004). Geç Bizans Dönem Yortanlı insanlarında da yine bu anomalinin yüksek frekansta olması dokuma tezgahının pedallarının kullanımında ayak ile alt bacak arasındaki mesafenin uzun süreli dar tutulmasıyla ilişkili görülmüştür (Nalbantoğlu, Türk ve Nalbantoğlu, 2000). 
Yilmaz Usta, N.D. (2015). Some teeth and skeletons anomalies reflected social-cultural practives of archaic people. International Journal of Social Sciences and Education Research, 1 (2), 547-559.

\subsubsection{Osteoartirit (kireçlenme) ve osteofitler}

Halk dilinde kireçlenme olarak bilinen osteoartirit iskelet kalıntılarında eklemlerdeki kıkırdağın altındaki kemiğin kalınlaşması ve kenarlarında küçük kemik çıkıntıları olan osteofitlerin oluşmasıyla tanımlanmaktadır. Osteoartiritin ve bunun sonucunda meydana gelen osteofitlerin gelişiminde yaş, genetik faktörler, mesleki zorlanmalar, travmalar, duruş bozuklukları, eklemlerin kötü kullanılması gibi faktörler rol oynamaktadır (Aydın, 2014). Eklemin aşırı yüke maruz kalması veya yaralanması osteoartiritin başlıca sebepleridir. Bu yüzden bu anomali özellikle eklem sistemini zorlayan hareketleri yapan insanlarda daha sık görülmektedir (Goodman, Martin, Armelagos ve Clark, 1984; Ortner ve Putschar, 1985).

İskelet kalıntılarında omurlarda görülen osteoartirit boyun, sırt ya da bel omurlarını etkilenme derecelerine göre sırt ya da başın üzerinde ağır yükler taşındığını yansıtır. Tarımla uğraşan toplumlarda buğdayın kol gücüyle ögütülmesine bağlı olarak diz ve dirsek eklemlerinde osteofitler gözlenmektedir. Gün boyu çıplak ayakla engebeli arazilerde koşuşturan insanların da ayak parmak kemiklerinde, eklem yüzeylerinin kenarlarında fazla kemik çıkıntılar oluşmaktadır (Özbek, 2004).

\subsubsection{Schmorl Nodülü}

Omurlar arasında bulunan kıkırdakların zayıflaması ve kendi içlerinde fitıklaşması sonucu meydana gelen omur içi bel fitığıdır. Doğumsal olabileceği gibi omurlarda meydana gelen zayıflamayla artan disk basıncının bu bölgeyi delmesi gibi dejenerasyon sonucunda da oluşur (Kotil, 2012). Antropoloji araştırmalarında schmorl nodülünün yüksek frekanslarda görülmesi insanların yaşamlarında omurgaya ciddi ağırlık yükleyen fiziksel aktiviteler yaptıklarını yansıtmaktadır (Açıkkol Yıldırım, Gözlük Kırmızığlu, Genç, 2012; Özdemir ve Sevim Erol, 2010).

\subsubsection{Kemik kırılmasl}

Genel olarak düşme, çarpma esnasında veya silahlarla yaralanma sonucunda oluşan kemik kırıkları insanların içinde bulunduğu çevre hakkında bilgiler sağlar. Örneğin Çatalhöyük Neolitik Çağ iskeletlerinde kafa travmasının özellikle erkeklerde yüksek olması bu insanların yüz yüze yapılan kavgalara maruz kaldıklarına işaret etmiştir (Angel, 1971). Geç Kalkolitik-Erken Tunç Çağı'na tarihlenen Kovuklukaya insanlarında gözlenen yüksek oranlardaki kafatası ve vücut kemiklerindeki travmalar da çevrenin engebeli olması ve sarp yamaçlardan oluşmasına bağlanmış, böyle bir arazide bu insanların sıklıkla düşme kazalarına maruz kaldıkları öngörülmüştür (Erdal, 2004).

\section{Dişlere yansıyan kültürel uygulamalar ve günlük aktiviteler}

\subsection{Dişlerin besin türlerini yansıtması}

İnsanların beslenme ve besin hazırlama kültürü dişlerinden anlaşılabilmektedir. Örneğin tarımın başlamasıyla taş değirmenlerde buğday öğütülerek tüketilmiştir. Bu esnada besinlerin arasına değirmen taşından kopan küçük parçacıklar karışmış ve insan dişinde ileri derecede aşınmaya neden olmuştur (Özbek, 2004). 
Yılmaz Usta, N.D. (2015). Antik insanın sosyokültürel yaşamını yansıtan bazı diş ve iskelet sistemi anomalileri. International Journal of Social Sciences and Education Research, 1 (2), 547-559.

\subsection{Dişlerin araç olarak kullanılması}

Bazı toplumlarda dişler sosyal yaşamda gündelik işler için kullanılabilmektedir. Örneğin denizcilikle uğraşan Iasos insanları halat iplerini dişleri arasında işledikleri için ön dişlerde bant görünümlü aşınmalar oluşmuştur (Yılmaz Usta, 2012). Neanderthal insanlarının ön dişlerinde kaydedilen ileri derecedeki aşınmaların da hayvan derilerini dişleri arasında çiğneyerek yumuşatmaları sonucunda oluştuğu belirlenmiştir. Yumuşattıkları derileri giysi olarak düzenleyen bu insanlar dişlere sosyoekonomik anlamda önemli görevler yüklemişlerdir (Kottak, 2002).

Pipo kullanımına veya mesleki alışkanlıkla iğne, çivi gibi araçların dişler arasında tutulmasına bağlı da kültürel aşınmalar oluşabilmektedir. Böyle örneklerdeki aşınmalar dişin temas ettiği materyalin şeklini almıştır. Temasın uzun süreli devam etmesi sonucunda dişin diş özü odacığ 1 (pulpa boşluğu) dahi açığa çıkmaktadır (Çelik, Özgünaltay ve Attar, 2007).

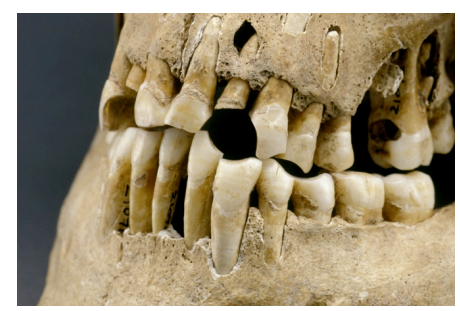

Resim 7. Ağızda pipo tutulması sonucu oluşan diş aşınması örneği (http://newsdesk.si.edu/sites/default/files/ photos/patux_jp_1000.jpg, 17.11.2015).

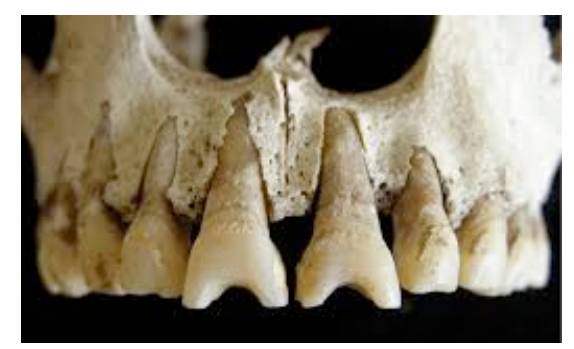

Resim 8. Diş tacının yontulmasıyla yapılan süsleme örneği (http://rachelwentzbooks. blogspot.com.tr/2013/09/biting-bling.html, 17.11.2015).

\subsection{Dişlerin estetik, ritüel ya da büyüsel olarak kullanılması}

Dişlerde gözlenen şekilsel değişikliklerin anlamı bir topluluktan diğerine veya kültürden kültüre farklı olabilmektedir. Bunlar güzelleşmek için uygulanan bir gelenek olabileceği gibi dinsel ya da büyüsel amaçla yapılmış kültürel bir pratik de olabilmektedir.

Dişin çekilmesi: Bu kültürel dental deformasyonla ilgili geçmiş dönemlere ait ve günümüzde de uygulanan birçok örnek vardır. Sahra Çölü bölgesinde Üst Paleolitik Çağ'da (Üst Yontma Taş Çağı) yaşamış olan Asselar topluluğunda erkeklerin üst kesici dişlerinin söküldüğü; Filistin Shongbah bölgesindeki kazılarda bulunan kadın kafataslarında ise alt kesici dişlerin birey hayatta iken bilinçli olarak çekildiği kaydedilmiştir. Günümüzde de Okyanusya'da Yeni Hebrid takımadalarında yaşayan Big Nambos yerlilerinde evliliğe hazırlanan genç kızların üst orta kesici dişleri çekilmektedir (Özbek, 2000; 2015).

Diş tacının alınması, yontulması veya diş tacına dövme yapılması: Günümüzde Vietnam'ın güneyinde yaşayan Moi kadınlarında üst kesici ve köpek dişlerinin taçları ince bir testereyle kesilip alınmaktadır. Afrika Fildişi sahilinde yaşayan yerlilerde üst kesici dişlerin eğik biçimde yontulması tükürüğü uzağa atmayı kolaylaştırması amacıyla uygulanan bir pratiktir. Bu toplulukta samimi bir selamlaşma tükürüğün uzağa atılmasıyla gösterilmektedir. Bugün Çin-hindi yarımadasında yaşayan Endonezya kökenli Mnong yerlilerinde ise üst ön dişlerin büyücü-dişçi tarafından kesici aletlerle yontularak testere biçiminde şekillendirildiği, bu uygulamanın erkekliğe geçişin bir ön koşulu olduğu belirtilmektedir (Özbek, 2000; 2015). 
Y1lmaz Usta, N.D. (2015). Some teeth and skeletons anomalies reflected social-cultural practives of archaic people. International Journal of Social Sciences and Education Research, 1 (2), 547-559.

Dişlerin kakma, dövme ya da delme yoluyla süslenmesi: Orta Amerika'da Neolitik Çağ'da yaşamış Kızılderililerin iskeletlerinde dişe kakma yöntemiyle değerli taşların sabitlendiği kaydedilmiştir. Günümüzde Hindistan'da yaşayan seçkin aileye mensup insanların dişlerine ortadan delinerek metal bir çubuk geçirilmektedir. Yine bazı toplumlarda estetik amaçlı ya da zenginlik göstergesi olarak ön dişler altınla kaplanmaktadır. Kuzey ve Orta Amerika'da yaşayan bazı yerli gruplarda ve bazı Afrikalı kabilelerde dişlere kırmızı renkte kalıcı olmayan cila yapılmakta; Güneydoğu Asya ve Çinhindi'de ise kalıcı siyah renkte cila uygulanmaktadır (Özbek, 2000; 2105).

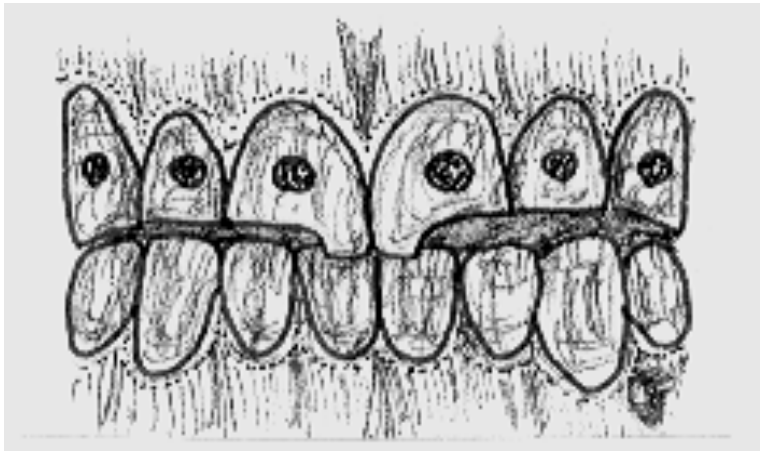

Resim 9. Dişe kakma yöntemiyle değerli taşlar yerleştirilmesi (http://www.uic.edu/classes/osci/osci590/6_1TheCulturalModificationOfTeeth.htm, 17.11.2015).

\section{Sonuç}

Derleme sonuçlarını raporlandırdığımız bu yazıda anomaliye sebep olan kültürel pratikler ve günlük aktiviteler ele alınmıştır. İskelet sistemine yansıyan kültürel uygulamalar arasında başın biçimini değiştirme, başı dağlama, kafa derisi yüzme, kafatası delgi ameliyatı (trepanasyon), ayak küçültme (ayak dondurma / lotus ayak) ve boyuna halka takma incelenmiştir: Başın biçimini değiştirme, ayak küçültme ve boyuna halka takma pratikleri soylu bir aileye mensup olmayı ve dini bir inanışı sembolize etmeleriyle birlikte, zaman içerisinde özellikle kadınlar için önemli bir güzellik unsuru haline gelerek estetik bir uygulama olmuşlardır. İncelediğimiz araştırma yazılarında başın biçiminde oluşan deformasyonun bilinçsiz olarak yapılan bir kültürel uygulama neticesinde de oluştuğu görülmüştür. Ayrıca, ayak küçültme ve boyuna halka takma işlemlerinin oldukça zahmetli olmasına karşın uzun yıllar uygulana geldiği gözlenmiştir. Başı dağlama ve kafatası delgi ameliyatı ise geçmişten günümüze uygulana gelmiş geleneksel sağaltma yöntemlerindendir. Tıp tarihi açısından oldukça önem arz eden bu uygulamalar ritüel ve büyüsel yönleriyle de dikkat çekmektedirler. Kafa derisi yüzme ise esasen bir savaş geleneği olup bu kültürel uygulamadaki amacın zamanla nasıl değiştiği de açıkça görülmektedir.

İskelet sistemine yansıyan günlük aktiviteler içerisinde ise çömelme faseti, schmorl nodülü ve osteoartirit (kireçlenme), osteofit (küçük kemik çıkıntılar) ve kemik kırıkları anomalileri ele alınmıştır. Konuyla ilgili taradığımız yayınlarda çömelme faseti bağdaş kurma, diz üstüne çökme gibi oturma hareketlerinin yaygınlığını göstermektedir. Kireçlenme (osteoartirit) ve buna bağlı gelişen küçük kemik çıkıntılar (osteofit) ve omurgadaki schmorl nodülü gibi anomaliler vücuda binen aşırı yüklere işaret etmekte; kemik kırıkları ise çevrenin topografik özellikleriyle ve bireyler arasındaki kavgalarla ilgili belirleyici bilgiler sağlamaktadır.

Dişler besin hazırlama tekniğini yansıtması, bir araç işlevi görmesi ve estetik, ritüel ya da büyüsel amaçlarla kullanılması açılarından irdelenmiştir. Besin hazırlama şekli insanın bir kültürü olmakla beraber hem tüketilen besin türü konusunda hem de besin oluşturma teknikleri açısından 
Yılmaz Usta, N.D. (2015). Antik insanın sosyokültürel yaşamını yansıtan bazı diş ve iskelet sistemi anomalileri. International Journal of Social Sciences and Education Research, 1 (2), 547-559.

incelenen insanların hangi seviyede oldukları hususunda belli başlı bilgilere ulaşmamızı sağlar. Antropolojik analizlerin incelenmesi esnasında dişlerini bir araç gibi kullanıp onlara sosyoekonomik anlamda önemli görevler yüklemiş insanların varlığı da ayrıca dikkat çekmektedir. Bunun yanı sıra dişleri arasında pipo, iğne, çivi gibi aletleri tutmayı alışkanlık edinmiş insanların bu davranışlarıyla da ilgili olarak dişlerinde anomalilerin oluştuğu belirlenmiştir. Günümüzde yaşayan bazı topluluklarda ise dişlere estetik, ritüel veya büyüsel işlemler uygulandığı tespit edilmiştir. Dişlerin bazı kabilelerde evlenmek, erişkin olmak gibi yaşamın belirli evrelerini anlamlandırdığı veya bu organlara birtakım kültürel pratikleri kolaylaşması için yeni şekiller kazandırıldığı görülmüştür.

Sonuçta, geçmişten günümüze uygulana gelmiş bazı sosyal davranışların ve kültürel pratiklerin insan biyolojisini etkilediği ve insanın dişlerinde ve iskelet sisteminde anomalilere sebep olduğu açıkça görülmektedir. Diş ve iskelet sistemi anomalilerinin bazılarının bilinçli olarak uygulana gelmiş bir geleneğin sonucunda oluşan anomaliler olduğu; bazılarının sağaltma amacıyla yapılmış işlemlerden kaynaklandığı; bazılarının ise günlük yaşamda sıkça yapılan aktiviteler ile ilişkili olarak yük taşıma, yürüme, oturma gibi hareketlerin veya mesleki bir davranışın etkisinde oluştuğu tespit edilmiştir. İnsan iskelet kalıntılarında bu izlerin teşhis edilmesi, antik insanın yaşamını aydınlatmasının yanı sıra bazen adli bir vakada bile gerekli bir ipucu olması açısından antropoloji çalışmalarında ayrıca önemli olduğu anlaşılmıştır.

\section{Kaynakça}

Açıkkol Yıldırım, A., Gözlük Kırmızıoğlu, P. ve Genç, E. (2012). Kuriki Höyük İskeletleri. Arkeometri Sonuçları Toplantısı, 29, 203-215.

Alpagut. B. (1986). The Human Skeletal Remains from Kurban Höyük (Urfa). Anatolica, 13, 149-174.

Angel, J.L. (1971). Early Neolithic Skeletons from Çatal Höyük Demography and Pathology. Anatolian Studies, 21, 77-98.

Angel, J.L. ve Bissel, S.C. (1986). Health and Stress in an Early Bronze Age Population. In M. I Mellink, (Ed.). Ancient Anatolia: Aspect of Change and Cultural Development (pp. 12-30). Medison: University of Wisconsin.

Aufderheide, A.C. ve Rodriguez-Martin, C. (1998). The Cambridge Encyclopedia of Human Paleopathology, Cambridge University.

Aydın, B.K. (2014). www.drkeremaydin.com/?displaywp_project=omuz-kireclenmesi erişim: 11.11.2015.

Aydın, S. ve Erdal, Y.S. (2007). Antropoloji. Eskişehir: Anadolu Üniversitesi.

Çelik, Ç., Özgünaltay, G., Attar, N. (2007). Diş Aşınmaları. H.Ü. Diş Hekimliği Fakültesi Dergisi, 31 (2), 22-30.

Dlamini, N. ve Morris, A.G. (2005). An Investigation of the Frequency of Squatting Facets in Later Stone Age Foragers from South Africa. Int. J. Osteoarchaeology, 15, 371-376.

Durmuş, İ. (2012). Türk Kültür Çevresinde Dağlama Geleneği. Milli Folklor, 95, 114-121.

Erdal, D.Ö. (2004). Eklem Hastalıklarının Yaşam Biçimiyle İlişkisi: Eski Anadolu Toplulukları Örneği. (Yayımlanmamış doktora tezi), Hacettepe Üniversitesi, Ankara.

Eren, H. ve Gözaydın, N. (1988). Türkçe Sözlük. Türk Dil Kurumu Yayınları, Ankara.

Goodman, A.H., Martin, D.L., Armelagos, G.L. ve Clark, G. (1984). Indicate of Stres from Bone and Teeth, Paleopathology in the Origins of Agriculture, USA: Academic Press. 
Y1lmaz Usta, N.D. (2015). Some teeth and skeletons anomalies reflected social-cultural practives of archaic people. International Journal of Social Sciences and Education Research, 1 (2), 547-559.

Jones, K. (2007). Interpreting behavior from the human skeleton: looking at squatting facets (Yayımlanmamış doktora tezi). Illinois State University, United States.

Kotil, K. (2012). www.tavsiyeediyorum.com/makaleler/11971-SCHORMLNODuLu.pdf.

Kottak, C.P. (2002). Antropoloji Insan Çeşittiliğine Bir Bakış. S.N. Altuntek, B. Aydın-Şafak, D. Erdal, Y.S. Erdal, S. Eroğlu, E.G. Ersoy, S. Özbek, S. Özbudun, Ş. Pala, G. Uysal (Çev.). Ankara: Ütopya Yayınevi.

Nalbantoğlu, E., Türk, H., Nalbantoğlu, C. (2000). 1996 yılı Yortanlı İskelet Popülasyonu Üzerine Paleoantropolojik, Paleodemografik ve Etno-Arkeolojik Çalışmalar, Türk Arkeoloji ve Etnografya Dergisi, 1, 27-36.

Ortner, D.J. ve Putschar, G.J. (1985). Identification of Pathological Conditions in Human Skeletal Remains. Washington DC: Simithsonian Institution Press.

Özbek. M. (1985). Değirmentepe Eski İnsan Toplumlarının Demografik ve Antropolojik Analizi. Arkeometri Sonuçlan Toplantısı, 1, 107-130.

Özbek. M. (1974). Etude de la deformatlan cranienne artificielle chez les Chal-colithiques de Byhlos (Liban). Bull. et Mem. de la Soc. d'Anthrop. De Paris. T. I. serie 13, 455-480.

Özbek, M. (2000). Dünden Bugüne İnsan. Ankara: İmge.

Özbek, M. (2003). Değirmentepe (Kalkolitik Çağ) Bebeklerinde İlginç Bir Adet: Baş Dağlaması. Belleten LXVII (249).

Özbek, M. (2004). Çayönü’nde Insan. Ankara: Arkeoloji ve Sanat.

Özbek, M. (2014). Trepanasyon Eski Çağlarda Beyin Ameliyatı. Aktüel Arkeoloji Dergisi, 42, 98-105.

Özbek, M. (2015). Irklara Veda Yaşasın Biyolojik ve Kültürel Çeşitlilik. Ankara: İmge.

Özdemir, S. ve Sevim Erol, A. (2010). Minnetpınarı İskeletlerinin Paleopatolojik Açıdan Analizi. A.Ü. DTCF Antropoloji Dergisi, 23, 95-127.

Şenyürek. M. S. ve Tunakan, S. (1951). Şeyh Höyük İskeletleri. Belleten XV, (60).

Tunakan, S. (1964). Bodrum-Dinnil Kazıs1 İskeletleri. Belleten, 28, 361-372.

Yılmaz Usta, N.D. (2012). Iasos (Bizans Dönemi) Toplumunun Diş Sağlı̆̆ı Açısından Anadolu Toplumları Arasındaki Yeri. (Yayımlanmamış doktora tezi), Ankara Üniversitesi/Sosyal Bilimler Enstitüsü, Ankara.

http://dunyalilar.org/kucuk-ayak-buyuk-statu.html

http://old.kesfetmekicinbak.com/atlasdan/eskiatlas/00165/

http://tmjbeverlyhills.com/skull-deformation-tmj-dentist-beverlyhills/

http://www.guncelmersin.com/haber/egitim-kultur_1/turkiyede-basarili-bir-antik-beyin-ameliyati/422.html

http://m.galamagazin.com/fotograflarla-cinde-yasayan-ayaklari-baglanmis-son-kadinlar/729/

http://opereysin.com/arastirma/1187-uzun-boyunlar-cokkun-omuzlar/

http://www.fotografturk.com/uzun-boyunlu-kadinlar-p297720

http://newsdesk.si.edu/sites/default/files/photos/patux_jp_1000.jpg

http://www.uic.edu/classes/osci/osci590/6_1TheCulturalModificationOfTeeth.htm

http://rachelwentzbooks.blogspot.com.tr/2013/09/biting-bling.html 
Yılmaz Usta, N.D. (2015). Antik insanın sosyokültürel yaşamını yansıtan bazı diş ve iskelet sistemi anomalileri. International Journal of Social Sciences and Education Research, 1 (2), 547-559.

\section{Extended abstract in English}

Some social-cultural activites on the men's life effect on their biological structures and so bring about some anomalies on teeth and skeletons. The main purposes of the study are identified anomalies bringing about cultural practices and daily activities that had have in place from prehistoric times to present on teeth and bones; are explicated questions how these anomalies are diagnosed and how they are interpreted; and are approached these social and cultural anomalies with anthropological perspective. To these ends, it is surveyed books, articles, periodicals and research reports having reference to anthropological analysis such as health status, paleopathology, paleodemography, life styles, cultural practives of archaic people, and add to cultural practives and conditions are grounded on cultural practives of people who lived at present. During the observation, it is determined cultural practices and daily activities that lead to anomalies on bone tissue make up of skeletal system and on teeth deliberately, and the study is majored in these subjects. By reason of the study, it is revealed which parts of human body were effected by cultural practices and daily activities and what anomalies are given occasion to cultural practices and daily activities, and tried to quote how social and cultural life of archaic people are deciphered by the mediation of answers of previous questions.

In this article reported collected datas, cultural practices and daily activities bringing about anomalies are undertaken at two superscription. The former is "the skeletal anomalies reflected social - cultural practives". It has two subtitles. The first of these is "cultural practices reflecting on skeleton system". At this chapter, it was examined five cultural practices including cranial deformation, cauterization, scalping, trepanation, foot binding and the tradition of wearing neck rings in turn. Cranial deformation, foot binding and the tradition of wearing neck rings symbolized belonging to a good family or having a religious affiliation, moreover they have been an aesthetic practices as a beauty demonstration for women after a while. In research papers, it has been observed cranial deformation could also occur as a result of doing a cultural practices unconsciously. It has been seen the foot binding and the wearing neck rings have been practiced over many years although they are very painful. Cauterization and trepanation are traditional treat methots pacticed from past to present. They have been included in this study on account of leaving a permanent mark on bones. These practives that being very impartant in the history of medicine also draws attention to the rituals and magical ways. The scalping was a tradition that had been applied in the war, but goal of this practice has changed in the length of time. The other subtitle is "daily activities reflecting on skeleton system". At this chapter, it has been surveyed squatting facets, osteoarthritis and osteophytes, schmorl' node and fractures respectively. In publications read on the subject, it has been seen squatting facets occur doing such seating movement as lotus position or collapsing knees in daily routines frequently. It has been observed schmorl's node and asteoarthritis effected on vertebras come out of external stress, and related to such activities as carry weight on back or on head. It has been viewed osteophytes (new bone formation at the bone margins) on foot bones also relate to standing up and walking a long time.

The latter is "the dental anomalies reflected social - cultural practives". In this chapter, teeth were explicated in terms of reflecting food repearation techniques, using as a tool, and processing as aesthetic, ritual and magical objects. In addition to being a culture of people, the food preparation techniques allow us to achieve a certain information both on the type of food consumed and about what level they had accessed. The teeth have been installed an important role in terms of 
Y1lmaz Usta, N.D. (2015). Some teeth and skeletons anomalies reflected social-cultural practives of archaic people. International Journal of Social Sciences and Education Research, 1 (2), 547-559.

socio-economic such as chewing animal skins to making clothes or chewing rope to making fishing nets. And also, some peoples have had the habit of keeping tools as pipes, needles, nails between their teeth. In some populations lived in past or at present, the teeth have been also practiced aesthetic, ritual or magical acts. In some tribes, the teeth gives meaning to certain stages of life such as marrying or comin of age; or they are given new shapes in order to ease some cultural practives. It has been observed the teeth used for the purposes as mentioned above create anomalies in them.

Consequently, it has been determined some of these dental and skeletal anomalies occured as a result of consciously applying a tradition; some grew out of treatment methods; and others occured because of activities of frequently doing in daily that are carried weight, walking, sitting, or working. It has been seen recognitions these anomalies are very important in terms of both reconstruction of life of archaic people, and also identification in a criminal case from skeleton. 